DOI 10.37882/2500-3682.2020.08.12

\title{
ЛОГИКО-ФИЛОСОФСКИЕ КАТЕГОРИИ В «НАУКЕ ЛОГИКИ» ГЕГЕЛЯ КАК ВАЖНЫЙ МЕТОД НАУЧНОГО ПОЗНАНИЯ СОВРЕМЕННОСТИ
}

\section{LOGICAL AND PHILOSOPHICAL CATEGORIES IN HEGEL'S «SCIENCE OF LOGIC» AS AN IMPORTANT METHOD OF SCIENTIFIC KNOWLEDGE OF THE PRESENT}

\section{Kozlov}

Summary: The article deals with the history of preparation and publication of the book, as well as theoretical concepts aimed at reforming formal logic and creating a new dialectical logic on its basis.

Based on the latest research of natural social and humanitarian disciplines, in the "Science of logic" Hegel forms and develops, significantly expands and deepens the categorical apparatus of philosophy and logic, expresses many deep and original ideas that have become a theoretical method and methodological basis in science, and have not lost their relevance today.

Keywords: Hegel, science, dialectics, theory, logic, concept, categories, thinking, truth, cognition.

\section{Введение в проблему исследования}

реди философских трудов, вошедших в золотую сокровищницу мировой философской мысли, важное место занимают произведения гениального немецкого мыслителя Г.В.Ф. Гегеля (1770-1831).

Вся философия Гегеля является чрезвычайно многогранной и имеет истинно энциклопедический характер. Его произведения остаются в сознании человечества, в истории его духовно-культурного развития. В своей философской системе немецкий мыслитель значительное внимание уделял логике как науке о законах и формах правильного мышления. Гегель неоднократно подчеркивал, «что только правильное мышление есть знания и познание предмета, и поэтому наше познание должно быть научным» [1, с. 58].

Гегель, прежде всего, в науке видел важный фактор развития человека, его творческих способностей, культуры мышления. В этом аспекте мыслитель считал необходимым кардинально изменить свою так называемую старую формальную логику и на ее базе создать качественно новую, которая бы отвечала современным реалиям жизни и служила эффективным орудием познания

\author{
Козлов Иван Иванович \\ К.ф.н., дочент, Российская академия музыки \\ имени Гнесиных \\ i.kozlov@gnesin-academy.ru
}

Аннотация: В статье рассматривается история подготовки и публикация книги, а также, теоретические концепции направленные на реформирования формальной логики и на ее базе создание новой диалектической логики. Основываясь на новейших исследованиях природных социально-гуманитарных дисциплин, В «Науке логики» Гегель формирует и разрабатывает, значительно расширяет и углубляет категорийный аппарат философии и логики, высказывает много глубоких и оригинальных идей, которые стали теоретическим методом и методологической базой в науке, не потеряли своей актуальности и сегодня.

Ключевые слова: Гегель, наука, диалектика, теория, логика, понятие, категории, мышление, истина, познание.

и анализа социальной действительности.

Следует отметить, что в системе профессиональной подготовки юристов особое внимание уделяется формированию научного мировоззрения. В этом аспекте важную роль играет овладение широким спектром философских знаний, что позволяет на этой основе формировать логическую культуру. Итак, «Наука логики» - это важное орудие творческого овладения логико-философскими идеями прошлого как важного фактора формирование личности будущего специалиста.

Философско-логические идеи Гегеля еще при его жизни вызвали живой интерес и много численных дискуссий. Среди его поклонников было немало талантливых, оригинальных личностей не только в Германии, но и за рубежом, в том числе и в России. Следует напомнить, что у философа были не только критики, но и откровенные противники его философских идей, которые существуют до сих пор.

Вся философская система Гегеля - это комплекс глубоких не только чисто философские, но и политико-правовых, экономических, моральных, эстетиче- 
ских и религиозных идей. Изучение и анализ которых является очень сложным и требует высокой теоретико-философской и логической подготовки.

Проблема философского учения Гегеля, а также его логических концепций, была предметом анализа многих зарубежных и отечественных ученых, среди которых известные русские философы И. Андреев, В. Асмус, К. Бакрадзе, А. Гулыга, Е. Ильенков, Д. Керимов, М. Киссель, Н. Мотрошилова, И. Нарский, В. Нерсесянц, М. Овсянников, Т. Ойзерман, М. Розенталь, Э. Ситковский, П. Федосеев и другие.

Отдавая должное исследователям научного творчества Гегеля, следует указать и на то, что до этого времени ряд логико-философских проблем не стали предметом полноценного научного анализа. Считаем целесообразным рассмотреть некоторые вопросы, освещенные в «Науке логики», и их теоретико-методологическую роль для формирования философско-логической культуры будущих специалистов и ученых в России.

\section{Изложение основных результатов исследования}

«Наука логики» (так называемая «Большая логика») созданная Гегелем в нюрнбергский период его жизни. Первая ее часть («Объективная логика», кн. 1 - «Учение о бытии») была опубликован в марте 1812 года. Вторая часть-в 1813 г. и третья - в 1816 г. Логику Гегель подразделяет на три части:

1. Логика бытия.

2. Логика сущности.

3. Логика понятий.

Гегель чрезвычайно важное место отводил логике как науке, которая органично была включена в его философскую систему. Новую логику Гегель стремился разработать в соответствии со своим идеалом «истинной науки». Гегель поставил в «Науке логики» задача - осуществить в ней кардинальную реформу.

Вопрос о реформе логики затронут в свое время еще выдающимся немецким философом И. Кантом - родоначальником немецкого классической философии. «Начиная с первых своих работ, - отмечает А. Гулига, постепенно Кант приходит к выводу о том, что процесс получение нового знания не может быть теоретически достигнутым в понятиях формальной логики» [2, с. 92].

Кант заявлял, что так называемая «старая» логика после Аристотеля не сделала ни одного шага, ни вперед, ни назад, и что она является законченной наукой. Философ делает вывод о том, что логика не может быть органом (орудия) метода в анализе проблем теоретического познания окружающего мира. В этом аспекте Гегель полностью был солидарен с Кантом.
Гегель глубоко осмысливает историю логико-философских идей, начиная с античности. Он внимательно следовал и анализировал новейшие идеи и научные открытия своей эпохи. Работая над первым томом «Науки логики», Гегель переосмыслил и переработал огромное количество литературы, вместе с тем он считал, что эта работа не является совершенной и в будущем нужно приложить немало усилий для ее завершения. Анализируя роль и место так называемой «старой» логики, Гегель указывает, что ее «форма и содержание остались такими же, какими они по давней традиции передавались от поколения к поколению, причем, при этой передачи ее содержание все больше и больше становился худым и нищим; а в ней не чувствуется тот новый дух, который оказался в действительности» [3, с. 77].

Перед Гегелем встает вопрос, «что необходимо для того, чтобы создать новую науку?». Философ делает вывод, что в таком положении вполне « бесполезным является желание сохранить формы прежнего образования, когда изменилась субстанциальный форма духа [3, с. 5].

С одной стороны, Гегель говорит, что мы строим новую науку не на пустом месте, есть известные уже формы мысли, которые следует рассматривать как важный подсобный материал. А с другой стороны, он «дает нам слабую нить или мертвые кости скелета», так что в логике нужно начинать «с самого начала», осуществить ее «кардинальную перестройку» [3, с. 173].

Гегель не отвергает так называемую «старую логику» формальную, наоборот - он, как великий диалектик, видит в ней рациональное зерно, но особое внимание акцентирует на создании новой логики и обязательное включение ее в программу преподавания в учебных заведениях, и это прежде всего необходимо для «юношества, которое еще не вступило в круг интересов повседневной жизни» [3, с. 13].

В чем заключается задача новой логики? По мнению мыслителя, логическая мысль должна охватывать в себя все многообразие знаний и наук в разумную форму, удерживая их суть и отбрасывая все внешнее и несущественное.

Начиная изложение своей логики, Гегель, прежде всего, определяет ее предмет как «царство чистой мысли», как науки о «чистой идею», как науку об «идее в себе и для себя». «Логику, - пишет Гегель, - следует понимать как систему чистого разума, как царство чистой мысли. Это царство есть истина ... можно выразиться и так: это смысл, изображающий Бога, который в своей вечной сущности от сотворения природы и какого бы то не было конечного духа» [3, с. 103].

Гегель указывает, что «потребность понимать логику в более глубоком смысле, чем как науку о чисто фор- 
мальном мышлении, вызвана интересами религии, государства, права и морали [3, с. 111].

Стоит отметить, что в философской системе Гегеля «дух», «идея» - это духовная основа (начало), которая порождает реальный материальный мир - природу, общество, человека, а также человеческое сознание, ум, а в конечном результате ее мышления. Высшей категорией логики является абсолютная идея (абсолютный дух), которая является единством теоретического и практического ума, идеи достижения практических результатов. «Абсолютная идея, - говорил Гегель, - есть истинная жизнь, или жизнь в истинные». Итак, под абсолютным духом Гегель понимает: «Е. Ситковского понимает деятельность человечества на протяжении тысячелетнего развития всемирной истории» [4, с. 22].

«Если вообще логику, - говорит Гегель, - признают наукой о мышления, то под этим понимают, что это мышление составляет голую форму некоторого познания, что логика абстрагируется от всякого содержания» [3, с. 96]. Философ не согласен с такой точкой зрения. Он подчеркивает, во-первых, неудачно утверждать, что логика абстрагируется от всякого содержания, что она только учит правилам мышления, не имея возможности вдаваться в анализ мыслимого и его характера. Если, как утверждают, ее предмет - мышление и правила мышления, то она непосредственно в них имеет и свой только ему присущий смысл и в них она имеет также и вторую составную часть познания, некую материю, характер которой ее интересует [3, с. 96].

Во-вторых, заявляет Гегель, что представления, на которых до сих пор основывалось понятие логики определенной мере уже устарели, им пора полностью исчезнуть, чтобы понимание этой науки основывалось на более высокой точке зрения и чтобы она достигла вполне отличного вида [3, с. 96].

Задачей новой науки Гегель считает не только выяснения истинности различных форм мышления, но и их связь и развитие. Формы мышления являются формами достижения глубокого и всестороннего знания об окружающем мире, поскольку они движутся и развиваются в направлении до познания сущности предмета.

«Основное содержание «Науки логики», - отмечает М. Розенталь, - Это безусловно диалектическая теория развития и исследования тех форм мышления, которые способны выразить развитие» [5, с. 10-11].

Гегель не только разработал теорию и метод диалектики, но и показал, как эта диалектика действительно помогает установить правильный подход к предмету. Гегель обосновал принцип диалектического развития изменений как объективный закон, которому подлежит все сущее в мире. Логика совпадает с метафизикой, с на- укой о вещах, достигаемых в мыслях. Итак, диалектика, которую Гегель считает единственным правильным методом логики, - это единство учения о бытии и учения о познании. Логика как наука о мышление совпадает с наукой об объективном мире.

Гегель предлагает поделить логику на «объективную» и «субъективную». Объективная логика непосредственно занимает место онтологии.

«Субъективная логика - это логика понятия сущности, она является свободным, самостоятельным, что определяет внутри себя субъективное, или, вернее, сам субъект» [3, с. 119]. Другими словами, субъективная логика - это отражение в мышлении процессов и явлений объективно существующего мира.

Какую же задачу ставит перед собой Гегель? Гегель пытается взять все то ценное, что было накоплено в науке, и на этой базе создать такую логику, которая бы служила эффективным орудием достижения истины. Он стремился создать такую логику, в которой форма и содержание были бы неразрывно связанными, поскольку истина существует только в таком отношении. Мыслитель, прежде всего в логике видел эффективный метод научно-теоретического мышления, что является важным фактором движения мысли к новым результатам, как в теории, так и в практике. Такой наукой на глубокое убеждение Гегеля должна стать диалектическая логика.

Хорошо известно, что любая наука содержит понятия и категории. Особое значение в «Науке логики» немецкий ученый придавал категорийному аппарату науки. Уже стало аксиомой, что принцип вывод категорий логики впервые с непревзойденной полнотой в истории философии в «Науке логики» разработал Гегель. В этом произведении каждая категория занимает определенное место, находится в тесной связи и взаимоотношении с предыдущими и следующими ее категориями, а в целом совокупность категорий логики выражает закономерность теоретического процесса познания.

Согласно концепции Гегеля логические категории наполняются содержанием степени развития системы категорий на протяжении всей логики. У Гегеля категории - это нечто предыдущее, а диалектика реального мира - их простое отражение. Логические категории, считает философ, существуют еще до природы и человека, они являются «животворящей душой» природы и человека, суть которых - это только «прикладная логика» $[4$, c. 26].

Следует отметить, что в «Науке логики» Гегель включает в понятийный аппарат целый ряд новых категорий, чрезвычайно тщательно обращает внимание на способ построения из них единой системы [5, с. 29]. Важное значение мыслитель придает тому, чтобы соответствующая 
категория появилась в четко определенном месте логической системы и чтобы она была «рождена самим развитием содержательного логического рассуждения» [6, C. 177].

Определить содержание какой-либо категории, значит найти ее место в системе, установить отношение этой категории к остальным. Развитие категорий от низшей и простейшей до самой логической системе Гегеля является одновременно попыткой построения определенной иерархии ценностей. Система категорий отражает целостность и единство процессов и явлений объективного мира их внутренняя взаимосвязь.

Среди категорий, которые анализирует философ в первом томе, значительное место отводится таким, как «бытие» «конечное», «бесконечное», «количество», «качество», «мера». Очень интересным является диалектика анализа количественно качественных отношений. Это он иллюстрирует на примере морали. «В морали, поскольку моральное рассматривается в сфере бытия, имеет место такой же переход количественного в качественное. Именно из-за «больше» и «меньше» мера легкомыслия нарушается и появляется несколько совсем другое-преступление, само из-за «больше» и «меньше» справедливость переходит в несправедливость, добродетель в недобросовестность, добродетель в порок. И государство при прочих равных условиях приобретает разнокачественный характер из-за различия в их размере. Законы и государственное строительство превращаются в нечто иное, когда увеличивается размер государства и возрастает число государство имеет меру величины, превосходя которую она внутренне неудержимо распадается при том же государственном строительстве, которое при другом размере составило бы его счастье и силу» [3, с. 405].

В своей науке логики Гегель разрабатывает философские категории единичного и общего. Он указывает на их диалектическую связь, на взаимопереходы и на тождество противоположностей. Так, сформулирован мыслителем принцип единства диалектики, логики и теории познания означает, что любое человеческое знание не может быть абсолютным, исчерпывающим, конечным, а является лишь ступенью, этапом в бесконечном процессе развития научных знаний. Диалектические категории как категории познания согласно этому принципу тоже должны выражать определенные ступени, этапы на пути познания. Но фактически процесс познания прерывается, заканчивается после того, как абсолютная идея завершает процесс самопознания.

Следует указать на то, что в своих произведениях Гегель не применяет понятие «диалектическая логика», но все его труды в основном посвящены разработке логических проблем. Это было связано еще и с тем, что Гегель, начиная с первых шагов своей педагогической и научной деятельности, в всех учебных заведениях постоянно пре-

\section{подавал логику.}

Значительный вклад был сделан немецким философом в разработку проблемы методов научного познания. В своей «Науке логики» и других произведениях Гегель создал истинно философский, всеобщий диалектический метод. Это способствовало в основном правильному определению места и роли других методов познания, которые применялись в отдельных науках, раскрыть их диалектическая связь и взаимозависимость. «...Не могу считать, - пишет Гегель, - что метод, которому следовал в этой системе логики или, точнее, которого соблюдалось в самой себе эта система, не допускает еще значительного усовершенствования, многочисленных отдельных положений, но в то же время я знаю, что он единственно истинный» [3, с. 108].

Гегель указывал, что такие методы логики, как индукция и дедукция, анализ и синтез, историческое и логическое и другие методы, хотя они в отдельных случаях являются самостоятельными, но они не изолированы друг от друга, а являются составляющими системами методов познания. Мыслитель считал на то, что движение понятий, категорий, то есть само движение мышления и сознания, лежит в основе всех явлений и процессов природы и духовной жизни людей.

Итак, процесс логического познания - это обобщенный исторический процесс. М. Киссель замечает: «достаточно только сравнить гегелевскую систему категорий с той, которой пользовались его предшественники, например, Кант, чтобы не только понять, но и почувствовать, какой колоссальный объем эмпирического материала, самого разнообразного по содержанию «просеял» он в своем сознании, чтобы выделить из него, как он сам выражался «алмазную сеть категорий» [7, с. 102].

«Наука логики» Гегеля уже при его жизни неоднозначно воспринималась различными философскими школами. «Неопозитивистская философия, - пишет П. Копнин, - откровенно нигилистически подходит к оценке гегелевской логики, считая, что

Гегель ничего, кроме путаницы и тумана, не внес в ту науку, которая выступает с требованием ясности. Позитивисты ограничивают логику той проблематикой, которая входит в круг формально-логического исследования.

Гегель же ратовал за то, чтобы изучение форм мышления вышло за пределы формальной логики и чтобы рассматривать их с другой стороны, которая очень важна для понимания места форм мышления в процессе достижения истины» [8, с. 269]. Для Гегеля истина - это сложный долговременный процесс познания. К ней пролегает трудный и противоречивый путь человеческого духа.

Гегель неоднократно подчеркивал, что основная за- 
дача философии и логики - поиск истины. Истина-это неокрашенная монета, ее не положишь в карман в готовом виде. Истина достигается в ходе длительного развития познания, где каждый шаг является непосредственным продолжением предыдущего. Истина - это достигнутый результат и путь к нему. Форма, в которой существует истина, - это научная система. Никто не сомневается в поэтому, подчеркивал мыслитель, что для овладения наукой нужно затратить большие усилия. Истина прокладывает себе дорогу только тогда, когда пришло ее время, но не раньше. Ничто большое не осуществляется без страсти, но ни одна страсть, ни один энтузиазм не оживят то, что не поспело. Гегель провозглашал, что истина - это великое слово.

Анализируя вышеизложенное, следует отметить, что с момента возникновения и до сих пор логика как наука находится в процессе постоянного развития. Законы, категории, формы, методы и принципы современной логики создаются для обеспечения потребностей науки. Но наука постоянно развивается, процесс познания усложняется, а значит и логика должна изменять свою форму и содержание в соответствии с теми изменениями и потребностями, которые возникают в ходе развития науки и научного познания.

\section{Выводы}

Ценным достижением гегелевской философии была и остается диалектика, которая изложена в «Науке логики». В этом труде Гегель проанализировал законы и категории диалектики, обосновал тезис о единстве диалектики, логики и теории познания (гносеологии).

В своей «Науке логики» Гегель сформулировал и теоретически разработал целый ряд теоретико-методологических проблем, среди которых видное место занимает глубокий анализ логико-философского категориального аппарата. Основным нововведением было то, что немецкий мыслитель сумел сформировать уже из известных категорий четкую единую систему. В своей диалектической логике, в диалектическом способе анализа Гегель стремился разработать метод, опираясь на который, можно проникать в сущность предметов, их связи и отношения.

Философское осмысление категорий Гегелем имеет важное методологическое значение. Это означает, что определить содержание какой-либо категории значит найти ее место в системе, установить отношение этой категории к другим. Гегелевская система категорий отражает целостность и единство процессов и явлений объективного мира, их внутренний взаимосвязь.

При рассмотрении таких категорий формальной логики, как понятие, суждение, умозаключение, он строил их классификацию с реальным развитием познания, а в фигурах силлогизма видел реальное отношение вещей. Как и все на свете, категории и законы логики отражают объективно существующий мир, а их нарушение приводит к ошибкам в умозаключениях.

В своем произведении Гегель впервые в истории пытался разработать и развить, диалектические формы мышления, доказать, что только они являются истинными формами, которые воспроизводят реальные процессы. Гегель был реформатором науки о мышлении.

Важная задача, которая сейчас стоит перед учеными, - это сосредоточение внимания на необходимости систематического анализа не только всех существующих категорий, но и разработки новых, учитывая особенности и закономерности современного научного познания и социальной практики. Творческое и глубокое усвоение будущими специалистами логико-философских идей великого немецкого мышления будет способствовать формированию творческого мышления, что дает возможность повысить логическую культуру мышления, освоить необходимые знания, умело их использовать как в процессе обучения, так и в дальнейшей профессиональной деятельности.

\section{ЛИТЕРАТУРА}

1. Гегель Г.В.Ф. Философия права: пер. с нем. / Г.В.Ф. Гегель; ред. и сост. Д.А. Керимов и В.С. Нерсенянц; авт. Вступ. ст. и примеч. В.С. Нерсенянц. - М.: Мысль, 1990. -524 с.

2. Гулыга А.В. Гегель / А.В. Гулыга. - М.: Молодая гвардия, 1970. - 272 с.

3. Гегель Г.В.Ф. Наука логики: в 3 т. - М.: Мысль, 1970. - Т. 1. - 501 с.

4. Ситковский Е.П. Философская энциклопедия Гегеля: в 3 т. // Гегель. Энциклопедия философских наук. - М.: Мысль, 1974. - Т. 1. - 452 с.

5. Розенталь М. «Наука логики» Гегеля и марксистская наука логики // Гегель Г.В.Ф. Наука логики: в 3 т. - М.: Мысль, 1970. - Т. 1. - С. 5-74.

6. Мотрошилова Н.В. Принцип системности в «Науке логики» Гегеля // Вопросы философии. - 1970. - № 10. - С. 137-149.

7. иссель М.А. Гегель и современный мир. - Ленинград: Изд-во Ленинградского ун-та, 1982. - 152 с.

8. Копнин П.В. Диалектика, логика, наука. - М.: Наука, 1973. - 464 с.

(с) Козлов Иван Иванович (i.kozlov@gnesin-academy.ru). 